\title{
Introduction: The Character of Physicalism
}

\author{
Andreas Elpidorou ${ }^{1}$
}

Published online: 20 June 2017

(C) Springer Science+Business Media Dordrecht 2017

Not many issues in philosophy can be said to match, let alone rival, physicalism's importance, persistent influence, and divisiveness. To a first approximation, physicalism holds that everything that exists in our world is physical. An acceptance of physicalism commits thus one to a monistic worldview. Despite how variegated existing entities or properties might appear to be, everything that exists in our world is, according to physicalism, the same: namely, physical. Indeed, it is widely thought that physicalism demands not only that the non-physical (the chemical, the biological, the economic, the social, the mental, etc.) metaphysically depends on the physical but also that the non-physical is nothing over and above the physical. But what type of metaphysical dependence vindicates physicalism?

The aim of this editorial introduction is twofold. First, Sects. 1-8 offer a critical introduction to the metaphysical character of physicalism. In those sections, I present and evaluate different ways in which proponents of physicalism have made explicit the metaphysical dependence that is said to hold between the non-physical and the physical. Some of these accounts are found to be problematic; others are shown to be somewhat more promising. In the end, some important lessons are drawn and different options for physicalists are presented. Second, in Sect. 9, the six papers that comprise the special issue are introduced and summarized. Each contribution to the special is, in different ways, concerned with explicating the character of physicalism. New ways of formulating physicalism are assessed; old ways are defended; and the distinctions between physicalism,

Andreas Elpidorou

andreas.elpidorou@louisville.edu

1 Department of Philosophy, University of Louisville, Louisville, KY 40292, USA naturalism, and dualism are reconsidered. The special issue is neither the first nor the last word on the topic of the character physicalism. Nonetheless, it offers both an updated appraisal of our current understanding of physicalism and concrete proposals for how to move forward.

\section{Physicalism: Ontology and Metaphysics}

At the heart of physicalism lies an ontological (or if you prefer, ontic) thesis. ${ }^{1}$ To espouse physicalism is to make certain commitments about what types of things (objects, properties, events, states of affairs) exist in our world (Quine 1948; cf. Hellman and Thompson 1977, p. 310). ${ }^{2}$ If

\footnotetext{
1 Why "physicalism" and not "materialism"? No good reason really. Both terms are acceptable and the choice between them is ultimately idiosyncratic. "Physicalism" has the benefit of rendering the metaphysical view under discussion both more general (the extension of "physical," I presume, is larger than that of "material") and closer to present-day physics. "Materialism" has the benefit of showing how the metaphysical view under discussion has a historical lineage and as such relates to the views of Hobbes, Lucretius, and Democritus.

${ }^{2}$ It is often stated that physicalism is both a contingent thesis and one that has strong modal commitments (Lewis 1983; Jackson 1998; Stoljar 2015). Its contingency is manifested in the claim that physicalism is a thesis about our world and even if it is true, it did not have to be so. Furthermore, the acceptance of physicalism entails a necessary determination thesis, one that articulates requirements for all possible worlds that stand in a similarity relationship to the actual one. The precise modal commitments of physicalism, however, depend ultimately on one's understanding of nothing-over-and-aboveness. In fact, the truth of physicalism in the actual world, which requires, I assume, that the mental is nothing over and above the physical, might entail-depending on our understanding of nothing-over-and-aboveness-that there are no worlds in which the mental is basic. For an argument in support of such a conclusion, see Levine and Trogdon (2009).
} 
physicalism is true, every thing that both (contingently and concretely) exists and plays a causal role in our world is, in some sense, physical. ${ }^{3}$ Immaterial angels, ectoplasmatic lions, and Cartesian souls are not to be found in our world, whereas leptons, molecules, mountains, desks, minds, and democracies are. Physicalism, however, is not just ontology; it is also, and importantly so, metaphysics (Schaffer 2009). ${ }^{4}$ Physicalists do not aspire of conjuring up long lists enumerating what exists (Jackson 1994, 1998). Physicalism is instead advanced with the hopes of capturing the underlying structure of our world. It aims to tell us not only what exists but also how it exists: that is, how certain things are because of, arise out of, or hold in virtue of, some other things (Schaffer 2009; Rosen 2010). To use Karen Bennett's wonderfully suggestive term, most proponents of physicalism deny "flatworldism" (Bennett 2011, p. 28). They have long given up the idea that our world is (metaphysically) flat. Not everything according to their picture is metaphysically on a par. Some things (objects, properties, events) are more fundamental than others. Indeed, the physical nature of the world is claimed to be more fundamental than the economic, social, biological, and even mental nature of our world. The former stands as the ground for everything else. The non-physical nature of the world, in other words, holds in virtue of the world's physical nature and precisely because it depends on it in such a fashion, physicalists maintain that the non-physical is nothing over and above the physical. ${ }^{5}$

Three clarifications are in order. First, "physical" will be taken to denote the set of entities mentioned in either current physics or a slightly modified version of it. "Physical" is not co-extensive with "microphysical"; current physics contains branches of physics that deal with macroscopic

\footnotetext{
${ }^{3}$ Entities exist concretely insofar as they exist spatiotemporally. An entity can play a causal role in our world even if it is a mere effect and not necessarily a cause.

${ }^{4}$ Even characterizations of physicalism which insist that physicalism ought not to be understood as a thesis that is either true or false (e.g., Dove 2016; Ney 2008a; van Fraassen 2002) have to accept that physicalism is committed to certain metaphysical claims about the nature of the world. Otherwise, it is hard to see what the difference would be between physicalism and a naturalistic view according to which everything in the world can be understood in terms of the methods and vocabulary of natural sciences. In his contribution to this special issue, Gene Witmer (2016) considers the relationship between physicalism and naturalism.

${ }^{5}$ Most informal characterizations of physicalism asserts the metaphysical primacy of the physical. For the claim that according to physicalism the non-physical is nothing over and above the physical see, among many others, Byrne (1999, p. 348), Chalmers (1996, p. 41), Dowell (2006, p. 1), Jackson (1998, p. 9), Leuenberger (2008a, p. 145), Lewis (1994, pp. 51-52), Loewer (2001, p. 39), Melnyk (2003, p. 2), Pettit (1995, p. 142), Wilson (2005, p. 426).
}

phenomena, such as solid-state physics and astrophysics, and it is best to remain neutral as to whether these phenomena can be reduced without remainder to the microphysical. The phrase "physical nature of the world" will refer to the pattern of physical properties, relations, particulars, etc., that according to current (or slightly modified future) physics is instantiated in our world. "Non-physical" does not mean anti-physical, i.e., entities the existence of which is inconsistent with the truth of physicalism. Rather, "nonphysical" denotes things or entities that (a) are not found in the descriptions of the current (or slightly modified future) physics and (b) are assumed to exist contingently and concretely in our world. I am aware of the many difficulties that such a proposed articulation of "physical" faces (e.g., Hempel 1969, 1980; Chomsky 2000; Crane and Mellor 1990; Melnyk 1997). I will not, however, deal with them in this essay. My aim is not to define "physical" but to explore the metaphysical relationship that is supposed to hold between the physical (assuming that "physical" can be defined in some way) and everything else (the non-physical). ${ }^{6}$

Second, I distinguish between, on the one hand, "grounding" or "ground," and, on the other hand, "Grounding" (Wilson 2014). The lowercase terms are meant to denote an asymmetric relationship of metaphysical (or ontological) dependence without specifying its exact nature (Raven 2015). ${ }^{7}$ "Grounding" with a capital "G" refers to the primitive account of metaphysical dependence proposed by Fine (2001, 2012), Schaffer (2009), and Rosen (2010) and then developed by many others (e.g., Audi 2012a, b; Correia 2010, 2013; Raven 2012; Trogdon 2013a, b). Consequently, to say that the non-physical is grounded in the physical is to commit oneself to the claim that the non-physical holds in virtue of the physical without however taking a position on whether this relationship should be understood in terms of, for example, realization, composition, or even Grounding.

Last, to elaborate on a point made above, the assumption that physicalism is a dimensioned or non-flat view excludes certain metaphysical views from counting as forms of physicalism. For example, if the mental is identical to the physi$\mathrm{cal}$, then the latter cannot be more fundamental than the former. Thus, if physicalism is the view according to which

\footnotetext{
6 Different attempts to define "physical" are summarized and evaluated in Ney (2008b) and Stoljar (2015).

7 The holding of this relationship implies that one of the relata is more fundamental than the other (Cameron 2008; Schaffer 2010; Rosen 2010). Having said that, I do not mean this to be a claim about ontological (or metaphysical) dependence as such. There could be instances of ontological dependence that are symmetric. See, e.g., Barnes (2016) but also consider Berker (manuscript). All that I require is that insofar as physicalism is concerned, the dependence relationship assumed to hold between the physical and the non-physical is asymmetric.
} 
the physical is metaphysically privileged with respect to the mental insofar as the latter metaphysically depends on the former but not vice versa, then various identity theses will not be forms of physicalism as understood here.

The two facets of physicalism-the ontological and metaphysical-are not unconnected. Many of the existence questions that physicalists ask (Do social institutions exist? Do minds exist? Do macrophysical objects exist?) are answered only through reflection on the metaphysical structure of the world. For any purported existent entity $a$, physicalists have to determine whether $a$ holds in virtue of (= is nothing over and above) something else, $b$. If it does, and if $b$ is physical, then $a$ can be allowed into their physicalist universe. If there is no $b$ such that $a$ holds in virtue of it, then physicalists have to decide whether $a$ is a basic ingredient of the physicalist universe - $a$ fundamental - or not. If the latter, then they would have to deny $a$ 's existence. Finally, if $a$ holds in virtue of $b$ but $b$ is not physi$\mathrm{cal}$, then physicalists have to repeat the above process until they discover a physical ground that gives rise to $a$ via giving rise to $b$ or until they realize that there is no physical ground for $b$ and consequently for $a$ (because $b$ is either fundamental or non-existent). ${ }^{8}$

The procedure just described is obviously underspecified. Physicalists need to articulate the dependence relationship that is assumed to hold between non-fundamental (or derivative) entities and physical entities. What does it mean exactly to say that the non-physical metaphysically depends on the physical and in doing so it is rendered nothing over and above the physical? Is this dependence relationship one of supervenience, a priori entailment, realization, composition, Grounding, truthmaking, ${ }^{9}$ or something else? And whatever it is, what is the ontological status of such a relationship? Is it physicalistically unproblematic or not? That is, can physicalists allow it in their world without incurring unbearable ontological costs (Lynch and Glasgow 2003; Dasgupta 2014; Sider 2011)? In what follows, I present and evaluate different ways in which accounts of

\footnotetext{
${ }^{8}$ What happens if the in virtue relationship is not well-founded? Does physicalism require that there must be a final fundamental level? [See, e.g., Lewis (1994, p. 52)] Or is physicalism consistent with the possibility of an infinite descent of dependence ( $a$ holds in virtue of $b, b$ holds in virtue of $c, c$ holds in virtue of $d, \ldots$, ad infinitum)? Schaffer (2003, p. 507) argues that physicalism is an "irreparably fundamentalist doctrine." Physicalism, Schaffer holds, requires a fundamental level because in the absence of such a level one cannot draw a distinction between the primary (i.e., the physical) and the derivative. Montero (2006) and Levine and Trogdon (2009) respond to Schaffer.

${ }^{9}$ I will not discuss a truthmaking approach to physicalism. For an examination of whether physicalism can be formulated in terms of truthmaking, I direct the reader to Morris' contribution to this special issue (Morris 2016).
}

physicalism have made explicit the metaphysical dependence that is said to hold between the non-physical and the physical.

\section{Fixing}

A first attempt to capture the primacy of the physical with regard to the non-physical finds recourse in the idea of fixing.

(1) The physical is more fundamental than the non-physical if fixing the physical fixes the non-physical.

What does it mean to fix something or other? Certain characterizations of "fixing" will not do the requisite work. For instance, "fixing" cannot mean causing. First, Cartesian-type interactionist accounts of the relationship between mind and body (assuming that they are coherent) postulate causal relata that are not only metaphysically independent of each other but also equally fundamental. Second, causality is typically taken to be a relationship between distinct events, whereas metaphysical dependence holds arguably between indistinct events (or existents) (Rosen 2010; Schaffer 2016). Third, even though effects might in some sense arise out of (or be produced by) their causes (Hall 2004, p. 225), typical causal relationships do not establish metaphysical priority. Hemlock caused Socrates' death, but hemlock is not metaphysically prior to Socrates' death. ${ }^{10}$

Fixing could be understood differently. The physical fixes the non-physical insofar as the physical gives rise to the non-physical (or equivalently, the physical fixes the non-physical if the former suffices for the latter). Such an understanding of fixing supports the basic physicalist contention that the physical nature of our world completely determines its entire nature (be it mental, social, economic, biological). God is usually employed in attempts to make this idea vivid (e.g., Kripke 1980, 153 f.; Chalmers 1996, pp. 35-41). If physicalism is true, in order to create the world, God only had to create its physical nature. Everything else followed.

There is an obvious problem with this characterization of fixing as an explication of the idea that the physical is

\footnotetext{
${ }^{10}$ Alastair Wilson (2017)'s discussion of Grounding complicates matters. He distinguishes between nomological causation and metaphysical causation (only the former is mediated by a law of nature) and argues that Grounding should be understood as metaphysical causation. If Wilson is right then there is a systematic connection between Grounding and causation. Be that as it may, the claims made in this paragraph are about nomological causation which by itself fails to fix ontological dependence. See also Schaffer (2016, Sect. 4.5) for a discussion of the differences between causation and Grounding.
} 
more fundamental than the non-physical. Fixing, as a pattern of dependence between the physical and the non-physical, remains silent on the precise nature of the metaphysical relationship between the two. In fact, the physical can give rise the non-physical without necessarily rendering it nothing over and above it. The non-physical can be wholly distinct from the physical even if it is, in some sense, metaphysically necessitated by the physical (e.g., emergentism). Thus, the concession that the non-physical nature of our world is guaranteed by its physical nature fails to show that it is nothing over and above the physical.

Another approach is to treat "fixing" as interchangeable with a type of asymmetric existential dependence (Tahko and Lowe 2015). The physical nature of the world is more fundamental than the non-physical insofar as the latter existentially depends on the former but the former does not existentially depend on the latter. Accordingly, let us say that a set of properties $P$ fixes a set of properties $Q$ iff (a) necessarily, $Q$ is instantiated only if $P$ is instantiated and (b) it is not the case that, necessarily, $P$ is instantiated only if $Q$ is instantiated. The physical nature of our world is more fundamental than the non-physical since the nonphysical nature could not exist without the physical but the physical could exist without the non-physical.

A problem with such an account of asymmetric existential dependence comes from Fine's well-known criticisms of modal accounts of ontological dependence (Fine 1994a, b). Indeed, Fine's remarks show that asymmetric existential dependence is neither necessary nor sufficient for the kind of metaphysical dependence addressed here. First, consider the relationship between Socrates and the singleton set \{Socrates\}. Necessarily, if Socrates exists then Socrates is the member of $\{$ Socrates $\}$ and, necessarily, if $\{$ Socrates $\}$ exists, then Socrates exists. An asymmetric existential dependency does not hold between Socrates and $\{$ Socrates\}, even though an asymmetric metaphysical dependence does hold: \{Socrates\} metaphysically depends on Socrates but not vice versa. Consequently, asymmetric existential dependence is not necessary for metaphysical dependence or priority. But it is not sufficient either. Assuming that numbers are necessary existents, it is true that, necessarily, if Socrates exists then the number 2 exists. Yet it is not the case that, necessarily, if 2 exists Socrates exists. Consequently, Socrates asymmetrically existentially depends on 2, even though Socrates does not metaphysically depend upon 2.

\section{Supervenience}

Matters do not get any better when we move from fixing to supervenience. Attempts to define physicalism in terms of supervenience face serious problems-ones that have been known for at least three decades (e.g., Horgan 1993; Kim 1993a, b, 1998a; Schiffer 1987, pp. 153-154; Wilson 1999, 2005). Despite their shortcomings, supervenience-based formulations of physicalism have proved both remarkably recalcitrant and popular.

To be fair, advocates of supervenience-based characterizations of physicalism have often been upfront about the limitations of their approach (e.g., Jackson 1998). And at other times, they have been careful to restrict the scope of their accounts to minimal physicalism: a supervenience thesis that proponents of physicalism must accept and which can be used to test whether epistemic arguments against physicalism are successful (Chalmers 1996; Stoljar 2015; but see also Hill 2009 for a different and more damning assessment of the prospects of supervenience physicalism). For present purposes, the issue of whether supervenience gets us minimal physicalism will be put aside (see Montero 2013 and Montero and Brown 2017). The question at hand is this: "Can supervenience-based characterizations of physicalism capture the metaphysical primacy that the physical enjoys over the non-physical?" The answer is "no." Supervenience by itself is incapable of capturing the metaphysical character of physicalism.

Supervenience is a logical relation that is assumed to hold (typically at least) between two classes of properties: the supervenient properties and the base properties. Roughly put, the non-physical supervenes on the physical if and only if any two situations that are identical with respect to their physical properties are also identical with respect to their non-physical properties. Stated otherwise, non-physical supervenience on the physical guarantees that there cannot be a difference in the non-physical without a difference in the physical (Davidson 1970; Lewis 1986). Using supervenience one can offer the following characterization of the primacy of the physical:

(2) The physical is more fundamental than the non-physical if the non-physical supervenes on the physical.

The claim that there cannot be a difference in the nonphysical without a difference in the physical can be understood both as a claim about individuals and about possible worlds. The former approach yields an individual supervenience claim whereas the latter yields global supervenience, both of which come in different modal strengths (e.g., Kim 1984; Bennett and McLaughlin 2014; Leuenberger 2008b). Characterizations of physicalism have typically employed global supervenience so I shall restrict my attention to the global variety.

(2.1) The physical is more fundamental than the nonphysical if the non-physical globally supervenes on the physical. That is, the physical is more 
fundamental than the non-physical if for any worlds $w_{1}$ and $w_{2}$, if $w_{1}$ and $w_{2}$ have the same worldwide pattern of distribution of physical properties, then they also have the same worldwide pattern of distribution of non-physical properties. ${ }^{11}$

To hold that the non-physical globally supervenes on the physical is to assert the existence of a pattern of property variation. Just like fixing, however, supervenience remains silent on the precise nature of this pattern. The silence of supervenience ultimately leads to three interrelated problems for any attempt that aims to explicate fundamentality using supervenience. Given that I am covering well-trodden ground, I will be succinct.

(a) Supervenience is non-explanatory The fact that a supervenience relationship holds does not explain why it holds. However, physicalism as a metaphysical view demands an explanation as to why the non-physical is related to the physical in such a manner (e.g., Horgan 1993; Melnyk 2003; Schiffer 1987). What is it exactly about the non-physical that renders it nothing over and above the physical? ${ }^{12}$

(b) Supervenience is unsuited for metaphysical priority Different reasons speak in support of this contention. First, the fact that the non-physical supervenes on the physical does not guarantee that the latter is metaphysically prior to the former. As it is pointed out in McLaughlin and Bennett (2014), arguably, two possible worlds $w_{1}$ and $w_{2}$ cannot differ with respect to the instantiation of property $P$ without also differing with respect to the instantiation of not-P. But the relationship between $P$ and not- $P$ cannot be that of metaphysical priority: in most cases, $P$ does not hold in virtue of $n o t-P$. Second, the logical form of fundamentality (or ontological priority) is unlike that of supervenience. Fundamentality is asymmetric and irreflexive; supervenience is non-symmetric and reflexive (Kim 1984; McLaughlin and Bennett 2014; Rosen 2010; Schaffer 2009). Finally, fundamentality (or ontological priority) is a hyperintensional notion, but supervenience is not (Fine 1994a; Schaffer 2009). Consider the set of properties that any world necessarily has. There are no two possible worlds that have the same worldwide

\footnotetext{
11 Making the notion of global supervenience precise is no easy task. For some attempts and discussions see, Bennett (2004), McLaughlin and Bennett (2014), Leuenberger (2009), Paul and Sider (1992), Shagrir (1999) and Stalnaker (1996).

12 Kovacs (2016) argues that a pattern of both modal and set-theoretical facts is capable of giving rise to an explanation of metaphysical dependence. Kovacs's account can thus be read as a way of showing how necessitation (or supervenience) can be explanatory.
}

pattern of instantiation of physical properties but that differ somehow with respect to their necessary properties. Yet, the fact that such necessary properties globally supervene on physical properties, does not show that necessary properties metaphysically depend or hold in virtue of physical properties (McLaughlin and Bennett 2014; Fine 1994a).

(c) Supervenience is non-discriminatory Superveniencebased characterizations of the relationship between the physical and the non-physical are consistent with a robust, antiphysicalist emergentism according to which certain non-physical properties are metaphysically necessitated by physical properties and the metaphysically necessary connections between the physical and the non-physical properties are fundamental and sui generis (Horgan 1993, 2006; Kim 2005; Wilson 2005). Supervenience is incapable of properly distinguishing between physicalism and competing views. Consequently, it fails to come to terms with the type of metaphysical priority that physicalism assigns to the physical.

\section{Reductive Physicalism}

\subsection{Reductive Explanation}

Another attempt to show that the physical is more fundamental than the non-physical consists in providing "conceptual" analyses of all sentences that contain non-physical terms in terms of only physical and physically acceptable terms. The idea that we can actually provide such analyses of all non-physical statements is, I shall assume, a chimera. But the fact that such a project is in-practice untenable need not fetter one's ambitions. One can still offer a theoretical account of how such analyses could proceed and thereby make it plausible that the requisite redescriptions and definitions are, at least in principle, forthcoming. David Lewis advances precisely such an account (Lewis 1970, 1972).

For Lewis, an important component of the meaning of referential expressions is provided by a set of conditions that permit a subject to specify their reference given certain hypothetical scenarios or descriptions. For instance, one has a grasp of the meaning of "water"-in one sense of "meaning"- if one is able to determine the reference of "water" when one is provided with certain descriptions of how things are or might have been. Such reference conditions are assumed to be a component of the possession of the concepts or expressions under question and furthermore, they are taken to be common knowledge among competent speakers of the relevant language. Often one can 
even collect all such reference conditions associated with a set of terms in a single theory.

Abstracting from the details (for those see, in addition to Lewis 1970, 1972; Braddon-Mitchell and Nola 2009; Byrne 1999; Schwarz 2015), Lewis held that the meanings of theoretical terms are definable functionally, that is, by reference to their causal roles. In the case of psychological terms, one can provide a simultaneous functional definition of psychological terms via the use of a Ramsey sentence of the relevant psychological theory. And in doing so, psychological terms ("pain," "belief," "desire," etc.) are eliminable: they can be replaced "by their definientia" (Lewis 1972, p. 254). As such, we can rewrite psychological terms in a way that they wear their causal/functional nature on their sleeves. Of course, one need not stop at psychological concepts; one can carry the Lewisian analysis to all nonphysical statements and terms. That is, one can hold that all non-physical statements that are true about our world can be translated into statements containing functional-role concepts and then argue that the referents of such functional concepts are physical entities.

Lewis' account of how to define theoretical terms finds a natural home in the project of reductive physicalism. The project of reductive physicalism is often conceived as a two-step project. First, one defines the properties that are to be reduced functionally using Lewis' approach. Functional analysis of this sort is often an a priori process that aims to "[work] the concept of the property to be reduced 'into shape' for reduction by identifying the causal role for which we are seeking the underlying mechanisms" (Levine 1993 , p. 132). In other words, functional analyses turn nonphysical vocabulary into "materialistically kosher" terms (Horgan 1993, p. 556). Second, one finds the physical property that fulfills the functional role that was specified in the first step. Lewis explicitly uses this model in arguing for a certain type of psychophysical identifications (Lewis 1972). According to Lewis, mental states are individuated by their causal-functional profiles. And, indeed, folk psychology implicitly defines mental terms by their causalfunctional roles. That is, a mental state $M$ can be analyzed a priori to be the state that occupies causal role $R$. Now, if it can be shown empirically that brain state $B$ is the occupant/ realizer of the causal role $R$, then we can conclude that $M$ is identical to $B$. This idea is not exclusive to mental terms and states. It can be applied to all non-physical states with the hopes of showing how such states can be reduced to physical states (Kim 1998b, pp. 98-99; Jackson 1994 articulate similar reductive accounts).

There are two assumptions underwriting the project of reductive physicalism that ought to be made transparent. First, the non-physical phenomena that call for explanation are such that the terms that are involved in their respective theories can be analyzed functionally (Chalmers 1996, p. 44). Indeed, this assumption is crucial for the success of reductive physicalism. Without it, we have no reason to think that the phenomena that call for an explanation are amenable to a reductive explanation.

Second, the process of being able to identify the target non-physical phenomenon with a physical state or phenomenon that occupies the causal-functional role assigned to the non-physical phenomenon is thought to be enough to vindicate physicalism. We look at what our preferred theory of the world says-for example, current physics-and if something plays the causal-functional role associated with a non-physical phenomenon then the phenomenon in question has found a place in our worldview: the phenomenon is entailed (indeed, a priori entailed) by what our preferred physical theory says. In this way, reductive physicalism is capable of offering answers to all sorts of "location problems" (Jackson 1998). It allows us to say when and how a putative feature of our world has a place in our physicalist universe.

Putting these two assumptions together, we can see that the project of reductive physicalism offers a natural suggestion as how to construe the metaphysical priority of the physical.

(3) The physical is more fundamental than the non-physical if there is a reductive explanation of all non-physical phenomena in terms of physical phenomena.

Despite claims to the contrary, I think that this sort of reductive explanation of the non-physical to the physical fails to capture the spirit of physicalism, if physicalism is understood as a dimensioned metaphysical view. This claim might sound surprising. Yet, I believe it follows once we have understood the limitations of reductive explanation and its relationship to fundamentality (or primacy).

\subsection{Problems with Reductive Explanation}

Why doesn't (3) work? Why is it the case that reductive explanation is not sufficient to establish the primacy of the physical? To a first approximation, the reason is this: the fact that some theoretical terms (what Lewis calls "T-terms") can be defined in terms of a preferred vocabulary does not mean that the entities named by such vocabulary are metaphysically prior to the entities named by $\mathrm{T}$. It might be true that physical entities in this world meet the functional or causal roles associated with non-physical entities. But why should one conclude from this fact that the non-physical entities are nothing over and above the physical entities?

The point can be made most forcefully if we turn to psychological phenomena. Here, I am drawing on Block's (2015) criticism of reductive explanation. Assuming that 
psychological phenomena are multiply realizable, then it is possible that they can be found in a number of agents that are physically different from us. In each case there will be a reductive analysis of the phenomenon in question. Pain in humans, let us continue with philosophical fiction, is C-fiber stimulation; in octopuses, pain is something else. But such a reductive analysis fails to shed any light on the question of ground. What is exactly that which stands as the common ground of the multiply realizable mental phenomenon?

One possible suggestion is to follow Lewis in holding that having pain (and not pain itself) is a higher-order property that is common in humans, octopuses, and in any other organism that experiences pain. But such an attempt to locate commonality between different organisms fails to articulate any kind of physical similarity between the different pains. At most, what we have located is a functional commonality.

What if one were to say that multiply realizable phenomena are grounded in a disjunction? Accordingly, the ground of mental phenomenon $M$ is physical state $P_{1}$ or physical state $P_{2}$ or ... physical state $P_{n}$. Such an attempt to find ground seems unacceptable, at least from the perspective of physicalism. Again, there is no common physical ground, only the illusion of one. In virtue of precisely what does $M$ exist? The answer cannot be that $M$ holds in virtue of one of the physical states (e.g., $P_{l}$ ) that compose the disjunction, for $M$ could have been present even if the system or organism were not in that physical state. Thus, $\mathrm{M}$ is something over and above $P_{l}$. In turn, the ground of $M$ cannot be all of the disjuncts taken together: each disjunct suffices for $M$. So, the ground, it seems, can only be the disjunction. But what a disjunction tells us is a commonality or a general relationship that holds between the disjuncts. The ground that a disjunction reveals is functional not physical (Block 2015; Stoljar 2010). ${ }^{13}$

Should our search for ground be more fine-grained? Perhaps we should not be looking for that which gives rise to a mental state as a type but rather for the ground of tokens of mental states. "Don't ask what is the ground of pain, but rather what is the ground of this particular dull pain that I am having right now." Although dialectically available, such a move is incongruous with the mandates of reductive

\footnotetext{
13 In a different context, Paul Teller raises the same concern. He writes: "Now what, I want to ask, makes it appropriate to call a property 'physical' when it is such a disparate and infinitely long disjunction of disjuncts each of which is probably already an uncountable conjunction of finite physical descriptions? Yes, it is a Boolean combination of physical properties, but I feel that to call it 'physical' threatens to be misleading. Which physical characteristics is it that all the things satisfying the individual disjuncts have in common?" (Teller 1984, p. 59).
}

explanation as presented above (but see Braddon-Mitchell and Jackson 2007, p. 103). Indeed, the fact that mental states (such as pain) admit of a functional explanation suggests that we can talk about pain as such (or at least, human pain as a type) but if there is such a thing as pain as such (or human pain), then physicalism owes us an account of its ground: i.e., what is that in virtue of which pain occurs and renders it nothing over and above the physical? Furthermore, even if we move away from type of mental states and concentrate on tokens we still have not arrived at the requisite metaphysical dependence relationship that is supposed to hold between the physical and the mental. What is exactly the relationship between the mental and the physical, considered on the level of tokens? If it is one of identity, then both the token of pain and the specific physical state are rendered equally fundamental - they are one and the same after all. But if the relationship is not one of identity, then what is it? We are still owed an account of their relationship.

In sum, assuming reductive physicalism, what is shown is that given how things are, physical entities happen to occupy the roles associated with non-physical terms. And because they occupy those roles, the non-physical follows. What is absent from such an account is an explanation of how the physical nature of our world plays a distinctive role in grounding its non-physical nature. Reductive physicalism is more functionalism than physicalism.

I anticipate three objections.

Objection 1 I have misunderstood reductive physicalism. Proper reductionism denies that there is something in addition to the physical entities that are the occupants of the various roles that explicate the non-physical entities. There is no pain and no water, only the realizers of such entities. Thus, to ask what is the metaphysical relationship between pain and the physical occupant of the pain-role is to have misunderstood reductive physicalism.

Two thoughts. First, it is not clear that I am guilty of a misunderstanding of the project of reductive explanation. Consider, for example, Jackson's solution to the various location problems that arise for the physicalist (Jackson 1998). Jackson explicitly denies an eliminativist solution to such problems (1998, pp. 2-3) and offers instead as a solution his "entry by entailment thesis" $(1998$, p. 6). That is, a putative fact has a place in the physicalists' world if it is entailed by the way things are physically. Hence, there are two things that appear to exist (the putative non-physical fact and the way things are physically), the latter does not include in an obvious sense the former, and thus it is meaningful to ask about the metaphysical relationship between them (see also Nolan 2005, p. 8). Second, if contrary to my claims reductive physicalism has to be understood as an eliminativist position, then reductive physicalism now falls outside of the scope of this paper. Regardless of its merits 
and demerits, such an eliminativist take on reductive physicalism is not a dimensioned view.

Objection 2 I have misunderstood Lewis' version of reductive physicalism. Although Lewis looks like a functionalist, he is a type identity theorist: he identifies mental properties with certain neurophysiological properties (Lewis 1966, 1972, 1994).

Undeniably, there is something right with claiming that Lewis is an identity theorist, but that is not the whole story. Lewis might be an identity theorist but he is so by way of functionalism (Smart 2007). Although Lewis accepts as true that pain is identical to C-fiber stimulation (let us assume), he maintains that such an identity claim is contingent and kind-relative (Lewis 1994, pp. 59-60): pain is C-fiber stimulation only for humans and only at the actual world. "Pain" is a non-rigid definite description. Linguistically, it behaves similarly to "the state that plays the pain role" and as such it refers to different things in different contexts. It is this feature of Lewis' position that makes it hard to see how the mental is nothing over and above the physical. Whatever physical state we decide is the occupant of the causal or functional role of pain in humans, then that is pain. But the fact that in our world (or even in all possible worlds) C-fiber stimulation is, let us say, the occupant of the pain role does not explain how pain holds in virtue of or arises out of the physical. ${ }^{14}$

Objection 3 My objection to reductive physicalism cannot be right. It cannot be right because it is too strong. It is too strong because, if successful, it shows that the failure of reductive physicalism is not restricted to the relationship that holds between the mental and the physical. That is, if I am right, reductive physicalism comes short of accounting for the metaphysical relationship that holds between the physical and any non-physical functional entities or properties. But that is absurd. Isn't it? No one thinks that mundane phenomena and entities such as screwdrivers, cars, parties, etc. pose a threat to physicalism. No one thinks that one cannot explain or account for those phenomena and entities in a physicalistically acceptable manner.

My response I accept the description of my objection, but I deny the implication. My claim is not that higherlevel, functional entities and properties stand somehow as obstacles to physicalism insofar as they are ontologically inconsistent with the mandates of physicalism. The claim is a different one. It is this: if one is not an eliminativist

\footnotetext{
${ }^{14}$ I take the following passage from Lewis to support my reading of his position: "When we describe mental state $M$ as the occupant of the $M$-role...[i]t says nothing about what sort of state it is that occupies the role. It might be a non-physical or a physical state, and if it is physical it might be a state of neural activity in the brain, or a pattern of currents and charges on a silicon chip, or the jangling of an enormous assemblage of beer cans." (1994, p. 58).
}

about the higher-level functional entities and properties, then one ought to offer, I maintain, an account of the metaphysical relationship that holds between the physical and those higher-level entities and properties. Reductive physicalism offers a functional explanation of the relationship between the two. But such a functional explanation is not one that points out how the physical gives rise to the nonphysical. It simply shows that given that the physical does such and so, the non-physical follows. The emphasis is not on the physical but on the role that the physical plays. The physical is in a sense superfluous, replaceable in principle by alien entities. As such, I contend, reductive explanation does not ground the non-physical in the physical (Block 2015).

Of course, one can deny that physicalism ought to care for an asymmetric metaphysical relationship between the physical and the non-physical that renders the latter nothing over and above the former. Or one can respond by arguing that functionalism is all that physicalism needs; to ask for something more is to place the bar at an unreachable height. Fair enough. I am not pretending that such responses are not available. My claim is simply that such responses are not positive answers to the metaphysical question. They do not specify the metaphysical relationship that is assumed to exist between the physical and non-physical. They deny either that it exists or that is part of physicalism.

\section{A Priori Entailment}

In presenting reductive explanation and specifically in showing how it is thought to provide a solution to various location problems for physicalists (Jackson 1998), I stated that if $\Phi$ is reductively explained in terms of $P$, then truths about $\Phi$ are a priori entailed by truths about $P$. But in criticizing reductive explanation as failing to specify a relationship of metaphysical dependence, I paid no particular attention to this relationship of a priori entailment. Suppose now that the relationship between reductive explanation and a priori entailment is made explicit: $\Phi$ is reductively explained in physical terms, if truths about physics are such that a priori entail truths about $\Phi$. Does an articulation of reductive physicalism as a thesis about a priori entailment help matters? It does not.

There are important differences between entailment and the metaphysical relationship that is presumed to hold between the physical and the non-physical and which renders the first fundamental. A sentence $P$ might entail a priori a sentence $Q$ even if $P$ and $Q$ are both false. But $Q$ cannot metaphysically depend on $P$ : an in virtue relation cannot hold between false statements (or between the facts expressed by false statements) (Bolzano 1972; Tatzel 2002). Perhaps, the comparison then should be between 
entailment in cases in which both statements are true. But again this does not seem to yield the requisite relationship. First, every true sentence $P$ is entailed by itself. But the common view on metaphysical priority is that nothing is metaphysically prior to itself (cf. Raven 2015). Second, and more to the point, there are examples in which $P$ a priori entails $Q$, but the fact expressed by $Q$ does not hold in virtue of the fact expressed by $P$. Consider the following example given by Bolzano (1972) while presenting his account of ground. The sentence "well-functioning thermometers stand higher in summer than in winter" a priori entails that it "it is warmer in summer than in winter," yet the fact expressed by the latter does not hold in virtue of the fact expressed by the former. A priori entailment, therefore, does not seem by itself capable of providing us with the relationship of metaphysical dependence that we are looking for.

In Constructing the World, David Chalmers argues that one can relate scrutability to fundamentality and thus to metaphysical priority. He proposes and defends the following thesis: "When $A$ and $B$ are super-rigid truths, $A$ conceptually grounds $B$ if $A$ metaphysically grounds $B$ " (2012, p. 453). ${ }^{15}$ Whereas metaphysical ground is understood in line with the notion of Grounding explicated, among others, by Fine (2001), Schaffer (2009), and Rosen (2010), conceptual ground is offered by Chalmers as a more finegrained relation than scrutability. Roughly, a truth $B$ is conceptually grounded in truth $A$ if $B$ is analytically entailed by $A$ and $A$ is conceptually prior to $B$ (that is, the concepts involved in $A$ are prior to those in $B) .{ }^{16}$ If Chalmers is right, then one could characterize metaphysical grounding (or just Grounding) in terms of conceptual relationships. Consequently, one could hold that the physical is more fundamental than the non-physical insofar as physical truths conceptually ground non-physical truths.

Should proponents of physicalism accept Chalmers' proposal? Here is not the place to engage in a detailed evaluation of Chalmers' position. Still, I wish to mention the following. First, assuming that non-physical truths are conceptually grounded in physical truths and accepting the link between conceptual grounding and Grounding, then all that proponents of physicalism have shown is that the

\footnotetext{
15 A super-rigid expression is an expression that is both epistemically rigid and metaphysically rigid de jure: that is, the expression is such that picks out the same entity in all scenarios and worlds. For a discussion of the notion of super-rigidity, see the "Fourteenth Excursus" in Chalmers (2012).

${ }^{16}$ Chalmers discusses conceptual priority in Chap. 7, Sect. 2 of Constructing the World and offers different models of understanding this notion. According to his preferred model, a concept $C 1$ is prior to $C 2$ if the constitutive inferential role for $C 2$-i.e., how $C 2$ is applied to scenarios characterized by other concepts-is such that involves $C 1$ but not vice versa.
}

non-physical is Grounded in the physical. The question as to whether this result shows that the non-physical is nothing over and above the physical still remains. Indeed, as I will argue in Sect. 7, it is not clear that Grounding can do the requisite work for physicalists. Second, proponents of physicalism should think twice before adopting Chalmers' conceptual and metaphysical framework. One should not lose track of the fact that Chalmers' claims about conceptual grounding and its relationship to Grounding are reflective of and follow from his general philosophical views: these include views about the semantics of concepts, the nature of explanation and reduction, and the character of metaphysical inquiry. As it has been emphasized before, the acceptance of such views could pose serious problems for proponents of physicalism (Block and Stalnaker 1999; Byrne 1999; Elpidorou 2014). Thus, one should be careful of accepting too much of Chalmers' philosophical edifice, lest one finds oneself in a position that is impossible to defend physicalism.

\section{Realization}

Reductive physicalism fails to come up with the requisite account of metaphysical dependence that ought to hold between the physical and the non-physical. Does realization physicalism fare any better? The answer depends on the variety of realization physicalism that we have in mind.

Unfortunately, it is not easy to say clearly what realization is. There is a fair bit of disagreement as to how to understand the thesis of realization and how it can be applied to physicalism (Gillett 2002, 2003; Melnyk 2003, 2006; Poland 1994; Polger 2007; Polger and Shapiro 2008; Shoemaker 2007). For present purposes, I shall focus on two influential accounts of realization that have been employed in the service of physicalism: Andrew Melnyk's realization physicalism (Melnyk 2003, 2006) and Sidney Shoemaker's causal subset account of realization (Shoemaker 2001, 2007, 2011; see also; Watkins 2002; Wilson 1999, 2011). My aim is to examine whether such articulations of realization can provide an account of the primacy of the physical.

\subsection{Melnyk's Physical Realization}

Before considering Melnyk's realization account, it is useful to distinguish clearly between two types of properties: higher-order and first-order. A higher-order property is a property that involves quantification over other properties. A first-order property is one that does not. A higher-order property then can be truly predicated about a subject if the subject has some other properties that meet certain conditions or play a certain role. A functional property $F$ with 
associated role $R$, for example, is a higher-order property: its instantiation consists in the instantiation of a number of other properties in a manner that they play role $R$.

On one popular account of what realization is, realization is a relationship that holds between property instances or tokens (e.g., Melnyk 2003). But this is not the only account. One could also hold that realization is a relationship between types. Given that I will be focusing on Melnyk's account of realization, I follow Melnyk in understanding realization as a relationship between tokens. In his 2003 book, Melnyk characterizes realization as follows:

Token $x$ realizes token $y$ iff (i) $y$ is a token of some functional type, $\mathrm{F}$, such that, necessarily, $\mathrm{F}$ is tokened iff there is a token of some or other type that meets condition, $\mathrm{C}$; (ii) $x$ is a token of some type that in fact meets $\mathrm{C}$; and (iii) the token of $\mathrm{F}$ whose existence is logically guaranteed by the holding of condition (ii) is numerically identical with $y$. (21; see also Melnyk 2006, p. 129)

Suppose that after thinking hard about mousetraps we come up with a certain condition $C$ such that if something meets $C$, then that something is an instance of a mousetrap. Now, according to Melnyk's definition, a particular physical structure (e.g., the box that I bought from the hardware store today) realizes a mousetrap if and only if anything that meets condition $C$ is such that is necessarily an instance of a mousetrap, the item bought from the hardware store meets condition $C$, and that instance of mousetrap that is logically guaranteed by the fact that the item from the hardware store meets condition $C$ is identical to the mousetrap realized by the item from the hardware store.

Can this formulation of realization shed light on the purported metaphysical primacy of the physical? Consider the following claim:

(4) The physical is more fundamental than the non-physical if the latter is realized by the former

As it stands, (4) does not work.

First, Melnyk's characterization of realization leaves it open as to whether the realized token is identical with its realizer (2003, p. 21). However, in the present context the realizer better not turn out to be identical to the realized token. If $x$ realizes $y$, and $x$ and $y$ are identical, then it follows that $y$ also realizes $x$. The possibility of identity between the realizer and the realized renders realization non-symmetric (i.e., neither symmetric nor anti-symmetric). Metaphysical dependence of the sort that is capable of spelling out the primacy of the physical ought to be asymmetric (i.e., both anti-symmetric and irreflexive).

Second, and relatedly, the fact that the non-physical is realized by the physical does not preclude the possibility that the non-physical can also realize the physical. And this issue persists even if we preclude the identity of the realizer with the realized. As far as I can tell, this criticism was first presented in Francescotti (2010) (for a detailed response, see Melnyk 2016a). Here is an example. Take the physical type having a location and let us assume that this is a functional type and, necessarily, it is tokened whenever something meets condition $C$ (condition $C$ might be being able to be placed in a system of coordinates). ${ }^{17}$ Now let us ask whether a token of this physical type, e.g., being located at $x$, can be realized by an instance of the non-physical type birthday party. Given that we already specified that having a location is a functional type, then according to the account of realization offered above my birthday party will realize being located at $x$ if (a) my birthday party meets condition $C$ and (b) the token of the functional type having a location that is necessitated by the fact that my birthday party meets $C$ is numerically identical with being located at $x$. But both requirements can be satisfied. First, my birthday party meets condition $C$ : it is after all located at my house! Second, assuming that my house is located at $x$, then my birthday party necessitates the existence of the token being located at $x$. If this example is admitted, then realization is incapable of capturing the metaphysical priority that the physical enjoys over the non-physical.

In order to remedy these problems, one needs to specify the manner in which a physical token meets the condition associated with the essence of the higher-order realized property instance. It is in this spirit that Melnyk offers his characterization of physical realization. He writes:

A token $x$ of a functional type, $\mathrm{F}$, is physically realized iff (i) $x$ is realized by a token of some physical type, $\mathrm{T}$, and (ii) $\mathrm{T}$ meets the associated condition for F solely as a logical consequence of the distribution in the world of physical tokens and the holding of physical laws (2003, p. 23).

Using the notion of physical realization, we can then revise (4) as follows:

(4*) The physical is more fundamental than the nonphysical if the latter is physically realized by the former.

(4*) is a clear improvement over (4). First, if we insist that the non-physical has to be physically realized by the physical, then we are assigning a certain priority to the

\footnotetext{
17 Melnyk understands "functional type" liberally. It "refer[s] to any type whose tokening just is the tokening of some or other type that meets a specific associated condition, where this condition could be of any kind, and needn't be the playing of a causal role" (2006, p. 129).
} 
physical: it is in virtue of the physical facts (the distribution of physical tokens and the holding of physical laws) that the token of a non-physical functional type is realized. Second, even though it seems certainly plausible to hold that the non-physical is physically realized, it is not plausible to maintain (indeed, it appears to be false) that the nonphysical non-physically realizes the physical: the physical does not hold in virtue of various non-physical facts (see Melnyk 2016a).

Should $\left(4^{*}\right)$ then be accepted? One might worry that $\left(4^{*}\right)$ shares one of the shortcomings of reductive explanation: insofar as physical realization gives us a ground of the non-physical, it is a functional ground. A token of a nonphysical type is realized (it is made real) in virtue of the fact that its existence is a logical consequence of the tokening of a certain condition. So, the ground of the non-physical token is specified by condition $C$ and consequently it is functional not physical. But this is not necessarily so. The realized token might be a token of a functional non-physical type, but according to Melnyk, "functional type" ought to be understood broadly (see footnote 17). Thus, depending on how $C$ is spelled out-i.e., what type of properties figure in $C$ - the ground of non-physical tokens might after all end up being physical.

Daniel Stoljar objects to Melnyk's realization physicalism on grounds that there is no way to spell out $C$ in a way that does not render realization either identity physicalism or supervenience/necessitation physicalism (Stoljar 2010, pp. 123-124, 2015). According to Stoljar, the properties that are included in condition $C$-the condition that spells out the essence of the higher-order non-physical property that is assumed to be physically realized by the physicalare either physical or realized by physical properties. If the former, then realization physicalism "will stand revealed as holding a version of identity physicalism (one level up, as it were), and thus will face the multiple realization objection" (Stoljar 2015). If the latter, an infinite regress looms, and the way to stop it, according to Stoljar, is to accept a supervenience thesis.

Let us put aside the second horn of Stoljar's dilemmaMelnyk (2016a) shows that even if the properties involved in $C$ are realized by physical properties no infinite regress ensues-and focus instead on the claim that the properties involved in $C$ are physical. Does that show that realization physicalism is a version of identity physicalism?

It is instructive to consider what Melnyk writes in response to this objection:

[L]et us first ask whether, if a higher-order property

$P$ has an essence into which only physical properties enter, it follows that $P$ is one and the same as a physical property. It may indeed seem to follow, on the grounds that the property can be specified in purely physical terms. But we shouldn't count a property as physical just because it can be specified in purely physical terms. We are speaking here of a higherorder property; and an instance of a higher-order property owes its reality to the property instance that realizes it. But the realizing property doesn't have to be physical just because the property that it realizes can be specified in purely physical terms [...] Suppose, for the sake of a concrete example, that being a mousetrap has a higher-order essence that can be specified in purely physical terms. Plausibly, it is still metaphysically possible for a mousetrap to be realized by a well-organized team of immaterial spirits. But if it is possible, then a mousetrap could exist that had no physical parts at all, and it seems wrong to call the property of being a mousetrap physical if there could be a mousetrap that had no physical parts at all. It doesn't follow, then, that $P$ is one and the same as a physical property just because it has a higher-order essence into which only physical properties enter, and so the realization physicalist doesn't "stand revealed as holding a version of identity physicalism." (2016a)

What shall we make of the above passage? Melnyk's aim is to show that the fact that a higher-order property has an essence that can be specified solely in terms of physical properties does not suffice to render the higher-order property physical. And if it is not physical, then it cannot be identical to a physical property.

Melnyk's suggestion echoes a point made earlier. The fact that a property can be given a functional account that has a purely physical explication does not entail that such a property is nothing over and above the physical. But if that is so, isn't Melnyk's account also incapable of accounting for how the non-physical is nothing over and above the physical? If the essences of non-physical functional types are specified in purely physical terms and yet such properties fail to be physical-because they can be realized by entities incompatible with physicalism, as the quoted passage states-then realization physicalism does nothing to fix the metaphysical priority of the physical over the non-physical.

In addressing Stoljar's worry, it seems that we have left behind $(4 *)$. Melnyk's argument that the higher-order property being a mousetrap is not a physical property rests on the premise that it can be realized simpliciter by entities that are ontologically incongruous with physicalism. But even if such a possibility is admitted, it is not the case that the mousetrap can be physically realized by such entities. So, let us suppose that a non-physical property has an essence that is specified solely in physical terms and then ask whether it is meaningful to claim that such a non-physical property is not physical if it is physically realized. I do 
not see how. Under the assumption that the non-physical is physically realized by the physical, non-physical properties turn out to be physical properties, if their essences are spelled out exclusively in terms of physical properties.

Ultimately, it matters little how we settle the issue. Either higher-order properties are physical or not. If they are not, then realization physicalism is incapable of showing how non-physical properties are nothing over and above the physical. Indeed, realization physicalism offers no clear improvement over reductive physicalism. If however they are physical properties, then Stoljar's objection returns: realization physicalism appears to be a form of identity physicalism. And an identity thesis has the wrong features for establishing fundamentality. If the non-physical turns out to be identical to the physical, then not only is the former nothing over and above the latter, but also vice versa.

Stoljar's objection notwithstanding, realization physicalism carries the promise of giving rise to the sought-after relationship of metaphysical dependence. First, physical realization assigns a priority to the physical over the nonphysical. Second, and assuming that higher-order nonphysical properties both have essences that are explicated solely in terms of physical properties and are physically realized, then the non-physical is nothing over and above the physical. Third, physical realization is an internal relation insofar as the fact that $x$ physically realizes $y$ holds in virtue of facts about $x$ and $y$ (Melnyk 2016a, b). As such, the physicalist incurs no metaphysical costs by embracing physical realization. Finally, physical realization is hyperintensional insofar as it is more fine-grained than necessitation. If the physical physically realizes the non-physical, then the former necessitates the latter, but not everything that is metaphysically necessitated by the physical (e.g., singleton sets containing physical entities as their members) is physically realized by the physical.

For all these reasons, realization physicalism and Stoljar's objection are worthy of the physicalists' time. Perhaps there is a sense in which the non-physical is physical without, however, being identical to the physical. In that case, physical realization owes us an explanation of how that is possible. Note, however, that if the relationship between a non-physical higher-order property and its physical realizer is one of composition (and not of composition as identity, for this would not appease Stoljar's objection), then realization physicalism would need to be supplemented by the metaphysical (and likely primitive) notion of composition (pace Melnyk 2016a).

\subsection{Shoemaker's Subset Realization}

According to the "traditional" account of realization, of which Melnyk's version is one possible articulation, the realized property (or instance of property) is a higher-order property that is defined in terms of a functional role and the realizers of this property are the first-order properties (or property instances) that perform this role. Sydney Shoemaker advances an alternative articulation of realization and contends that it "provides the most revealing characterization of physicalism itself: physicalism, we can say, is the view that all states and properties of things, of whatever kind, are physical or physically realized" (Shoemaker 2007, p. 1).

For Shoemaker, properties are individuated in terms of their causal profiles. ${ }^{18}$ Although Shoemaker is a famous proponent of the causal theory of properties, i.e., the theory according to which properties have their causal profiles essentially (see Shoemaker 1980, 2007), he maintainsat least in his Physical Realization-that his account of realization physicalism does not presuppose such a strong view regarding property individuation. Instead, Shoemaker argues that all that is needed is the weaker view that each property "is individuated by a causal profile in the sense that it and it alone has the profile in the actual world and worlds nomologically like it" (2007, p. 142). As I point out below, and as Shoemaker ultimately concedes, this weak view does not secure physicalism. But, importantly, a substitution of this weak view with the stronger claim according to which properties have their causal profiles essentially is no solution either.

How does Shoemaker understand realization? One property realizes another just in case a certain membership relationship holds between the causal profile of the realizer and that of the realized (Shoemaker 2007, p. 12; cf.,2001, p. 78). Specifically:

Realization $_{\text {Subset }}$ Property $P$ realizes property $Q$ iff $Q$ 's causal features constitute a subset of $P$ 's causal features.

Does Shoemaker's version of realization account for the metaphysical priority of the physical over the non-physical? In other words, should (5) be accepted?

(5) The physical is more fundamental than the non-physical if the latter is realized subset $_{\text {by }}$ the former.

\footnotetext{
18 According to Shoemaker (2007, p. 12) the causal profile of a property includes both "forward-looking causal features" (how the tokening of the property gives rise to various effects) and "backward-looking causal features" (what are the states of affairs that can give rise to the instantiation of the property). Shoemaker no longer insists that the backward-looking causal features are part of the causal profile of a property. See Shoemaker (2011). This move is a return to his previous position on properties (Shoemaker 2001).
} 
There are at least two reasons that speak against (5). First, as it has been noted before, subset realization is insufficient by itself to guarantee the truth of physicalism (Kirk 2009; McLaughlin 2009; Stoljar 2010). Although Shoemaker insists that the "occurrence of realized states is 'nothing over and above' the occurrence of their realizers" (2007, p. 2), such a constitutive relationship does not follow from the weak account of property individuation. Consider, for example, the relationship between a mental property, $M$ and a physical property, $P$. $P$ will realize $M$ just in case the causal features of $M$ are a subset of those of $P$. Now if properties are contingently individuated in terms of their causal features $(2007$, p. 2, n. 2), then even though it might be the case that in the actual world the instantiation of $P$ (the physical realizing property) gives rise to an instance of $M$ (the realized mental property), it is not guaranteed that $M$ will be instantiated in all possible worlds in which $P$ is instantiated. And pace Shoemaker (2007), this difficulty does not disappear by expanding the realizer of $M$ to include not only $P$ but also the holding of the laws of nature that obtain in the actual world (see Kirk 2009, p. 150; McLaughlin 2009). Hence, it is a mistake to hold that the tokening of the mental property in question is nothing over and above the occurrence of its physical realizer. A subset account of realization fails to account for the metaphysical primacy of the physical over the non-physical.

In response to this difficulty, one could endorse Shoemaker's causal theory of properties and maintain that properties have their causal features essentially. Such a move is indeed one that Shoemaker himself makes in later works (see, e.g., Shoemaker 2011) and although it avoids the problem raised above, it does require the acceptance of a strong and, for some, controversial account of property individuation. Is this a fair price to pay? It is hard to tell. For present purposes, what matters is whether this stronger version of Shoemaker's account of realization can help us specify the metaphysical dependence relationship between the physical and the non-physical that we are after.

Suppose that we follow Shoemaker in holding that according to physicalism, all non-physical properties are physically realized. What this means is that the causal features of each and every instantiated non-physical property is a subset of the causal features of some instantiated physical property. But doesn't such an understanding of the relationship between the physical and the non-physical render Shoemaker's account of realization a form of identity thesis? (see Kim 2010 and Pereboom 2016 but also Wilson 2011) If non-physical properties are constituted by their causal features, and such causal features are, in virtue of the fact that non-physical properties are realized by physical properties, the features which constitute physical properties, then non-physical properties are physical properties after all. ${ }^{19}$ The point here is not that non-physical properties should be identified with their realizers but rather that non-physical properties just are physical properties. Subset realization is revealed as a form of identity physicalism and as such, it is a flat view. Hence, even if we grant that properties possess their causal powers essentially, subset realization physicalism still does not deliver the sought-after metaphysical relationship between the physical and the non-physical. ${ }^{20}$

\section{Grounding}

We have been looking for a relationship of metaphysical dependence that has the following features: (a) it holds between the physical and the non-physical; (b) it assigns metaphysical priority to the former; and (c) it renders the latter nothing over and above the former. Despite our best efforts, we came up short. Why is that?

One might suggest that the reason is simple. We could not find an account of the requisite metaphysical dependence by examining various existing formulations of physicalism because the relationship that we are after is primitive: it is Ground with a capital "G." Thus, proponents of physicalism who wish to capture the metaphysical nature of physicalism should offer a Grounding formulation of physicalism. In this section, I present this avenue for physicalists and raise a number of difficulties that need to be resolved (for more difficulties, see Wilson 2016). Just like the previous avenues considered, this is not a rosy road to take.

What is Grounding? It is common to take Grounding to be a primitive relation (Rosen 2010, pp. 113-114; Schaffer 2009 , p. 364) either between facts (as per Rosen 2010, Audi 2012a) or entities (as per Jenkins 2011, Schaffer 2009) that expresses a kind of constitutive form of determination dependence ["something like metaphysical causation" (Schaffer 2012, p. 122)]. ${ }^{21}$ Thus, to say that " $x$ Grounds $y$ "

\footnotetext{
${ }^{19}$ If it is possible for non-physical properties to be realized by properties which are incompatible with physicalism, then non-physical properties are not identical to physical properties: the causal features which are constitutive of the non-physical properties are not physical. In this case, however, the fact that such non-physical properties are actually realized by physical properties does not render them nothing over and above their physical realizers.

${ }^{20}$ For some other problems with subset realization that, for reasons of space, I cannot discuss, see Gibb (2014), Gillett (2010), and Pereboom (2011).

${ }^{21}$ I speak of Grounding as a relation. However, not everyone would agree with this presentation. For example, Fine (2012) and Correia (2010) take Grounding to be a non-truth-functional sentential operator that connects sentences stating the Grounds and sentences stating what is being Grounded. What is more, not everyone accepts that Grounding is primitive. See for example Bricker (2006).
} 
is to assert that $y$ holds in virtue of $x: y$ is what it is because of $x$. Proponents of Grounding maintain that such a notion helps one to structure reality (Schaffer 2009) and to distinguish between what seems to exist (but perhaps does not) and what really exists (Fine 2001; see, however, Audi $2012 \mathrm{~b}$ ). If the mental is Grounded in the physical, then the physical is more fundamental than the mental. The mental depends in a strong metaphysical sense on the physical (it is constitutively determined by it) and as such it could be considered to be nothing over and above the physical.

Because of its primitive nature, Grounding is often introduced with the help of examples (Correia and Schnieder 2012; Fine 2012; Raven 2015; Rosen 2010; Schaffer 2009). One cites plausible instances of Grounding and, on the basis of such instances, articulates the nature of Grouding by both relating it to and distinguishing it from other more familiar notions (e.g., explanation, supervenience, a priori entailment). One can also use Grounding in order to elucidate other notions (Schaffer 2009). All of this is done with the aim of characterizing Grounding without however reductively defining it.

The primitiveness of Grounding is, as one would expect, a mixed bag. On the one hand, it invites skepticism both in regard to its meaning and its use. Some have contended that Grounding is an esoteric or confused notion (e.g., Daly 2012; Hofweber 2009; Wilson 2014). Others complained that as a primitive coarse-grained metaphysical relation, Grounding is bereft of any real metaphysical use (e.g., Koslicki 2015; Wilson 2014): it fails to resolve the questions that is supposed to resolve. On the other hand, its primitiveness provides us with certain stipulative freedom and I shall take advantage of that freedom in using Grounding in formulating physicalism. Accordingly, I shall make the following assumptions:

(a) Grounding is irreflexive: nothing Grounds itself.

(b) Grounding is asymmetric: if $x$ Grounds $y$, then $y$ does not Ground $x$.

(c) Grounding itself is not an explanatory relationship even though it underwrites explanations (see, e.g., Audi 2012b; Schaffer 2012)

Requirements (a)-(c) are placed in order to allow Grounding to capture the relationship of metaphysical dependence that is assumed to hold between the physical and the non-physical if physicalism is true. ${ }^{22}$

\footnotetext{
${ }^{22}$ Requirement (c) is negotiable. That is for two reasons. First, some proponents of Grounding maintain that Grounding is an explanatory relation (Dasgupta 2014; Fine 2001). Second, one might argue that physicalism is at heart an explanatory position and the primacy of the physical ought to be captured in terms of an explanatory relation: it is the physical that explains the non-physical and not vice versa.
}

Consider thus (6):

(6) The physical is more fundamental than the non-physical if the non-physical is Grounded in the physical.

Now, if by definition " $\mathrm{x}$ Grounds $\mathrm{y}$ " means $x$ is more fundamental than $y$, then Grounding captures a type of metaphysical priority. That much is clear. What is not clear is whether (6) captures the type of metaphysical priority that physicalism assigns to the physical. In what follows, I consider three complications in an attempt to offer a Grounding formulation of physicalism.

\subsection{Grounding and Reduction}

Not every proponent of Grounding accepts that Grounded facts are nothing over and above their Grounds. In fact, it is consistent with Grounding that if the physical Grounds the non-physical, then the latter could be something over and above the former. For example, Audi writes: "The mere fact that some entity is grounded does not make it any more (or less) ontologically innocent. The grounded is every bit as real - and real in precisely the same sense - as that which grounds it" (Audi 2012a, p. 102). Although permissible by the rules of Grounding, such an attitude is at odds with physicalism. The non-physical cannot be over and above the physical. So, if Grounding is to be of use to proponents of physicalism, Grounded facts or entities have to be nothing over and above what Grounds them.

Here we see an immediate issue with Grounding. It does not suffice to say that physicalism is the view according to which the non-physical is Grounded in the physical and leave it at that. One also needs to articulate how Grounding captures the relationship of nothing-over-and-aboveness.

So, what does it mean to say that $y$ is nothing over and above $x$ ? In the present context, it cannot mean that $x$ and $y$ are identical (recall the features of Grounding). Following Trogdon (2013a), one could hold that $y$ is nothing over and above $x$ just in case the ontological commitments of the existence of $x$ are the same as that of the existence of $y$. (Trogdon offers this as an account of reduction. Here I am using it as an account of nothing-over-and-aboveness.) Such an account guarantees that the existence of $y$ "weighs," ontologically speaking, no more than the existence of $x$. The benefit of such an understanding of the notion of nothing-over-and-aboveness is that it allows Audi's claim that the Grounded is real, perhaps even as real as that which Grounds it, but without having to admit that the Grounded is something over and above its Grounds.

Despite its merits, such an understanding of nothingover-and-aboveness will not do for our purposes. Nothingover-and-aboveness understood in terms of ontological commitments is a symmetric relationship (Trogdon 2013a). 
As such, not only would the non-physical be nothing over and above the physical, but also vice versa.

A different understanding of nothing-over-and-aboveness can be found in Gideon Rosen's discussion of reduction (Rosen 2010, Sect. X). Rosen argues for the following claim: if $\langle\mathrm{p}\rangle$ (the proposition that $\mathrm{p}$ ) is true and reduces to $\langle\mathrm{q}>$, then $[p]$ (the fact that $\mathrm{p}$ ) is grounded in [q]. What is it for one proposition to reduce to another? According to Rosen, $\langle\mathrm{p}\rangle$ reduces to $\langle\mathrm{q}>$ if $\langle\mathrm{q}>$ is what we get when we offer a real definition (the definition of a thing/entity and not a verbal definition) (see Fine 1994a) of p. Take for example the property being a circle. Its real definition is this: a circle is the set of all points in a plane that are equidistant from a given point (the center). The real definition tells us then that what it is to be a circle and it also tells us how to generate one. There is nothing more to being a circle than what its real definition offers us. Thus, following Rosen we can say that (i) $<$ something is a circle $>$ reduces to $<$ something is the set of all points in a plane that are equidistant from a given point $>$ and (ii) if < something is a circle $>$ is true, then [something is circle] is Grounded in [something is the set all points in a plane that are equidistant from a given point].

How useful is this analysis to proponents of physicalism? As it stands, it is not very useful. Rosen's analysis offers a necessary condition for reduction. If we apply it to the case of the physical/non-physical, it tells us that if the non-physical reduces to the physical, then the physical Grounds the non-physical. The difficulty with this proposal is that now we need to figure out how to reduce (in Rosen's sense) the non-physical to the physical. And that means that we need to embark on a journey to figure out whether each non-physical existent has a real definition in terms of the physical such that the definition (i) does not render the non-physical identical to the physical and (ii) shows that reduction is both asymmetric (the non-physical reduces to the physical but not vice versa) and irreflexive (the physical does not reduce to itself, otherwise it would Ground itself). Perhaps such a task is achievable. But even if it is, the proponent of a Grounding formulation of physicalism has to show that the proposed reduction of the non-physical to the physical is different than the options considered above (e.g., realization or reductive explanation). In effect, in order to motivate a Grounding formulation of physicalism, the proponent of such a definition would need to provide us with a story of how the non-physical is nothing over and above the physical. We are (more or less) back where we started.

\subsection{Grounding and Necessitation}

Suppose that the non-physical is Grounded by the physical. Does that mean that the physical necessitates the nonphysical? Let " $\Gamma$ " stand for the collection of all physical facts and let us assume that $\Gamma$ Grounds a non-physical fact [q]. Does it follow that, necessarily, if all physical facts in $\Gamma$ obtain, then [q] obtains? Many proponents of Grounding accept that Grounding carries such a modal commitment (e.g., Audi 2012b; Dasgupta 2014; deRosset 2013; Rosen 2010; Trogdon 2013b). For example, Rosen (2010) writes that " $[t]$ he facts that ground a given fact collectively ensure that it obtains as a matter of metaphysical necessity" (118) and notes that such a necessary connection between Grounds and what is Grounded allows the proponent of Grounding physicalism to distinguish her position from dualism.

Although I am sympathetic to the idea that Grounding entails necessitation, not everybody agrees. Indeed, in the literature one finds counterexamples to claim that Grounding carries modal entailment (see, e.g., Leuenberger 2014; Schnieder 2006; Skiles 2015). Here, I am not interested in adjudicating this debate which is internal to the Grounding literature. Still, the debate matters to proponents of Grounding formulations of physicalism. If there can be instances of Grounding without (metaphysical) necessitation, then the question of whether the Grounded is nothing over and above its Grounds returns. A necessitation relationship is a necessary condition for nothing-over-and-aboveness: If the physical Grounds obtain and a non-physical Grounded fact does not, then something in addition to the physical facts is needed in order to make it the case that the non-physical fact obtains (see also Witmer 2001). Hence, an account of Grounding that does not entail that what is Grounded is necessitated by its Grounds would fail to capture the spirit of physicalism. ${ }^{23,24}$

\footnotetext{
${ }^{23}$ In the previous paragraph, I stated that $\Gamma$, the collection of all physical facts, Grounds a non-physical fact [q] and then asked whether it is possible for all physical facts in $\Gamma$ to obtain and for [q] to fail to obtain. One might accept that $\Gamma$ fails to necessitate [q] but deny that this shows that Grounding does not entail necessitation. That is because what Grounds [q] is not just $\Gamma$ but rather $\Gamma$ plus a totality fact-i.e., a fact that expresses that nothing more than physical facts obtain. So, both $\Gamma$ and a totality fact necessitate [q]. Although it is beyond the scope of this paper to evaluate this response, it is clear that, in this case, $\Gamma$ does not Ground the totality fact: otherwise, $\Gamma$ alone would be sufficient to Ground [q]. Consequently, proponents of physicalism would need to consider whether such a totality fact, which is not Grounded in the totality of physical facts, is consistent with physicalism. For a more detailed discussion of this issue, see Leuenberger (2014). Rosen (2010) also briefly discusses the nature of the totality fact within the context of Grounding.

${ }^{24}$ Even if Grounding does not entail metaphysical necessitation, it has been argued that Grounding entails a supervenience thesis that involves Grounds and what is Grounded: specifically, any two worlds that are indiscernible with respect to their Grounds are indiscernible with respect to what is Grounded (Leuenberger 2014; cf.; Schaffer 2016, n. 10). Such a result, however, offers little solace to proponents of physicalism who are interested in using Grounding as a way to spell out the relationship between the physical and the non-physical. Given the many problems with supervenience as an attempt to explicate metaphysical priority, the fact that what is Grounded (the nonphysical) supervenes on its Grounds (the physical) does not show that the former is nothing over and above the latter.
} 


\subsection{Grounding and Grounding Facts}

Lastly, according to our Grounding proposal, the physical Grounds the non-physical. But what exactly is the status of those facts about Grounding? Are they themselves Grounded in something or not? Questions about the status of Grounding facts have attracted the attention of both proponents and critics of Grounding (Bennett 2011; Dasgupta 2014; deRosset 2013; Sider 2011; Wilson 2016). Indeed, some have thought that the status of those Grounding facts constitutes an obstacle to Grounding formulations of physicalism (e.g., Sider 2011). Consider the following Grounding claim:

[GC]: The fact that Greece is a parliamentary representative democratic republic is Grounded in facts concerning voting regulations and the activities of the various governmental branches.

Is [GC] Grounded? Suppose that it is not. [GC] is then $\operatorname{arguably}^{25}$ fundamental. But [GC] involves in addition to facts about voting regulations and activities of governmental branches, mention of Greece and of parliamentary representative democracy. Such an involvement seems problematic. If physicalism is true, a fundamental description of the world better not include talk of Greece or types of democracies (Sider 2011; see also Dasgupta 2014; deRosset 2013; Trogdon 2013a). After all, they are supposed to be nothing over and above the physical. Physicalists would then seem to be committed to holding that $[\mathrm{GC}]$ is Grounded. But what fact would Ground [GC]? And if [GC] is Grounded in a fact, then that further fact would also need to be Grounded, and so on. A proliferation of Grounds and Grounding facts would ensue.

Bennett (2011) and deRosset (2013) both argue that $[\mathrm{GC}]$ is Grounded in a fact that it contains. More generally, if [p] Grounds [q], then [[p] Grounds [q]] is itself Grounded in [p]. Such a proposal also takes care the worry of an infinite regress: not only is [[p] Grounds [q]] Grounded in [p], but also [[[p] Grounds [q]] is Grounded in [p]] is Grounded in [p]. Hence, assuming that [Greece is a parliamentary representative democratic republic] is Grounded in physical facts about voting regulations and the activities of the various governmental branches, then [GC] itself, a fact about Grounds, is also Grounded in physical facts about voting regulations and the activities of governmental branches.

A different solution to the question of what Grounds [GC] is found in Dasgupta (2014). Without going into the details of his position, Dasgupta holds that [GC] is Grounded in facts concerning the essences of entities

\footnotetext{
25 Not everyone identifies the fundamental with that which is not Grounded. See, e.g., Sider (2011) and Wilson (2014).
}

involved in [GC] together with some other facts pertaining to [GC]. What is important for our purposes is that, according to Dasgupta, the facts concerning the essences of entities involved in Grounding facts are Ungrounded. Still, he denies that this feature renders them fundamental. Rather, what this shows according to Dasgupta is that such facts are "autonomous" insofar as they are not apt for having a Ground in the first place.

Both solutions have their merits. On the one hand, there is something right with Dasgupta's attitude that, at least within the context of physicalism, one need not Ground every single fact. Physicalism's scope is not unrestricted. It is not a theory about everything. Consequently, it is within physicalists' rights to exclude certain facts from the scope of their theory. On the other hand, Bennett and deRosset's suggestion is appealing to physicalists for a different reason. It shows that under the supposition that a non-physical fact is Grounded in a physical fact, then the fact that such Grounding fact obtains is also Grounded in a physical fact. Many things 'follow' from the physical: not only the non-physical but also the very relationship between the physical and the non-physical that renders the latter less fundamental.

Still, one might have concerns about both proposals. In the case of Dasgupta's proposal, one might worry that physicalists have over-restricted the scope of their position. Essentialist facts are still facts and by not providing an account of how they are Grounded we leave out a description of how things are (deRosset 2013). In the case of Bennett and deRosset's proposal, one might wonder whether their proposal offers a satisfactory explanatory connection between Grounding facts and their Grounds (Dasgupta 2014). Figuring out the force that such concerns carry is important. We would like to know whether they pose serious obstacles to Grounding formulations of physicalism. But even without having to figure that out, we can still note that Grounding formulations of physicalism face difficulties that appear to be internal to the notion of Grounding (see also Melnyk 2016a, b and; Wilson 2016). Although this conclusion does not amount to an argument against Grounding formulations of physicalism, it raises questions about the use and value of the notion of Grounding in formulations of physicalism.

\section{Lessons}

It is time to take stock. I do not have a single conclusion to offer. Or better, if I have one it is simply the observation that there is no quick and easy way to formulate the metaphysical character of physicalism. Nevertheless, proponents of physicalism are not without options and, indeed, I bring this essay to an end by listing six of them. Whichever one is adopted one thing is for sure: more work awaits proponents of physicalism. 
Option 1 Reject the view that physicalism ought to care for ground or metaphysical dependence. In fact, if reductive physicalism does not have room for ground, then so much the worse for ground. Barbara Montero's understanding of physicalism is consistent with this approach. According to Montero (2013), supervenience of the mental on the physical is not even necessary for physicalism. If Montero is right, then physicalism can survive on a metaphysics-free diet. If we do not need supervenience, then we do not need a stronger relationship of metaphysical dependence.

Option 2 Fine! Physicalism lacks physical ground. What it can offer, however, is a functional ground. And that is all that is needed. Functionalism is physicalism enough.

Option 3 Try to repair one of the accounts of physicalism that was evaluated in this paper. Realization physicalism seems to be the natural candidate since it fared better than the others. Or perhaps we should take to heart the idea that the relationship of metaphysical dependence in question is primitive and thus invest our efforts in the notion of Grounding.

Option 4 Look at other ways of formulating physicalism with the hopes of finding the requisite account of metaphysical dependence in them. Perhaps we should understand the relationship between the physical and the nonphysical in terms of composition (e.g., Pereboom 2011), part-whole relationship (e.g., Ehring 2003; Elpidorou manuscript), constitution (e.g., Baker 1997), or the determinate-determinable relationship (e.g., Yablo 1992; Wilson 2009). Neither approach is free of problems, but what else is new?

Option 5 Throughout the paper I held that identity physicalism does not have the right features to count as the relationship of metaphysical dependence that physicalism requires. Well, one might think that this is not a problem for identity physicalism. If anything, it is a problem for the relationship of metaphysical dependence that is assumed to hold between the physical and the non-physical. The lesson to draw is that the only version of physicalism that is worth our time is that of identity physicalism (e.g., Hill 1991, 2009; Polger 2004; Smart 1959).

Option 6 We should not bother with formulating physicalism and its metaphysical commitments. This might mean that there is no question of physicalism (Crane and Mellor 1990) or it might mean that we do not need a formulation of physicalism to address the important philosophical issues surrounding physicalism (Stoljar 2010). ${ }^{26}$

\section{The Special Issue}

The question "What is physicalism?" is in need of an answer as much as the question "Is physicalism true?" The goal of the special issue is to provide a forum in which a number of original essays can come together in order to contribute to our understanding of the nature of physicalism. In the pages that follow, one will find six original contributions that do precisely that. The issues taken up within the pages of this special issue are many and varied. As such, the papers are representative of the different approaches that proponents of physicalism have pursued over the years in trying to elucidate the nature of physicalism. Still, all papers are unified by their aim to better understand the character of physicalism and its commitments.

In "Physicality for Physicalists," Gene Witmer undertakes an investigation into how "physical" should be understood in the context of physicalism. When proponents of physicalism claim that every thing that exists is physical or that nothing is over and above the physical, what exactly do they mean by "physical"? It is well known within the literature on physicalism that there are important difficulties in explicating the meaning of "physical" in a way that is consistent with how physicalism is typically understood (Hempel 1969, 1980; Chomsky 2000; Crane and Mellor 1990 and Melnyk 1997). In fact, some have taken this difficulty to constitute an insurmountable obstacle to formulate physicalism and deemed that physicalism is not a position that can be meaningfully articulated. In his contribution, Witmer responds to such concerns. By providing a proposed account of "physical" that permits us to, as he puts it, "rationally manage" physicalism (i.e., assess various questions about physicalism and its relationship to other positions), Witmer shows that skepticism about the possibility of articulating physicalism is misplaced.

In the relevant literature, one finds attempts to characterize physicalism in many different ways. Just to name a few, physicalism has been formulated in terms of identity, supervenience, realization, part-whole relationship, composition, a priori entailment, and, more recently, Grounding. However, not a lot of attention has been given to the

\footnotetext{
${ }^{26}$ I am grateful to Kelly Trogdon for his discerning and thorough comments on a previous version of this paper and to Guy Dove for conversations on physicalism. I also thank Karen Bennett and Louis deRosset for generously addressing my questions about their respective positions. I would also like to thank audiences at the University of Louisville and at the 2015 meeting of the Society for the Metaphysics of Science for their patience and questions on issues related to this paper.
} 
possibility of formulating physicalism in terms of truthmaking. In "Physicalism, Truthmaking, and Levels of Reality: Prospects and Problems," Kevin Morris examines the prospects of a truthmaking formulation of physicalism. Despite initial attractions to this approach, Morris concludes by questioning the usefulness of a truthmaking approach to physicalism.

In previous work, Andrew Melnyk has advanced and defended a realization formulation of physicalism (Melnyk 2003, 2006). To a first approximation, Melnyk takes physicalism to be the view according to which every entity-token is either narrowly physical (i.e., it is a type of an entity that is mentioned in the laws and theories of more or less current physics) or physically realized by some narrowly physical entity-token. Melnyk's realization physicalism has proved to be tremendously influential and a number of authors have either adopted it or criticized it. In his contribution, "In Defense Of A Realization Formulation Of Physicalism," Melnyk considers and responds to various and important challenges to his position. In doing so, he offers an important and revised defense of realization physicalism.

The notion of Grounding is meant to illuminate the structure of reality: it purports to show how some phenomena arise out of or hold in virtue of some other more fundamental phenomena. If physicalism holds that the nonphysical depends in an important sense on the physicalism, then it is natural to ask whether Grounding can capture the dependence relationship between the non-physical and the physical. In "Grounding-based Formulations of Physicalism" Jessica Wilson considers precisely this question and evaluates the usefulness of Grounding in attempts to formulate physicalism. In her contribution to this special issue, Wilson offers a sustained, thorough, and if correct, devastating critique of Grounding formulations of physicalism. She argues that Grounding-based formulations of physicalism suffer from the following five shortcomings: (i) they lack motivation; (ii) they lack illuminating content; (iii) they conflate metaphysics and epistemology; (iv) they fail to distinguish between physicalism and emergentism; and (v) they give rise to problems that are specific to Grounding.

The majority of proponents and opponents of physicalism take physicalism to be a (metaphysical) thesis-a contentful claim that is either true or false. However, not everyone agrees with such treatment of physicalism. For example, Bas van Fraassen (2002) holds that physicalism should be understood as a stance one takes towards the world. And Alyssa Ney (2008a) has argued that physicalism is a type of attitude towards one's ontological commitments. In his contribution to the special issue, "Redefining Physicalism," Guy Dove is sympathetic in spirit to, and builds upon, such alternative understandings of physicalism. First, by presenting known and important difficulties with treating physicalism as a metaphysical thesis, Dove motivates the need for an alternative take on physicalism. Second, he argues that physicalism should be understood (or $r e$-understood) to be an interdisciplinary research program that encompasses physical sciences, psychological and brain sciences, and philosophy, and which aims to explain the mental in terms of the physical.

In the final contribution to the special issue, "Making Room for a This-Wordly Physicalism," Barbara Gail Montero and Chris Brown oppose what might be characterized as the orthodoxy on physicalism, namely, the view that at the very least physicalism requires that a supervenience relationship between the physical and the non-physical obtains. Montero and Brown reject Jackson's (1998) argument that physicalism is committed to such an entailment claim. Furthermore, they provide a number of scenarios that are physicalistically acceptable and yet in which the mental fails to supervene on the physical. Ultimately, they conclude that physicalism does not entail that the mental supervenes either logically or metaphysically on fundamental physical properties.

This special issue is truly a collective and collaborative enterprise. I would like to express my gratitude to the Editor-in-Chief of Topoi, Fabio Paglieri, for trusting me with the task of editing this special issue. I would also like to thank Mahalakshmi Mariappan for her tireless and invaluable editorial assistance. In turn, I am grateful to the following individuals who have served as reviewers for the special issue: Peter Bokolich, Andrei Buckareff, Sam Coleman, Erhan Demircioglu, Jonathan Eric Dorsey, Markus Eronen, Peter Fazekas, Raphaël Fiorese, Robert Francescotti, Benedikt Göcke, Aaron Griffith, Tang Weng Hong, Robert Howell, Andreas Hüttemann, Stephan Leuenberger, Joseph Levine, Patrick Lewtas, Patrick McGivern, Kelvin McQueen, Kevin Morris, Dwayne Moore, Alyssa Ney, David Pineda, Raphael van Riel, William Seager, Alexander Skiles, David Spurrett, Tuomas Tahko, Justin Tiehen, Kelly Trogdon, Agustin Vicente, and David Yates. Without a doubt, their constructive, patient, and rigorous reports have contributed to the quality of the special issue. Lastly, I would like to thank all the authors who submitted their work for consideration to the special issue. An overwhelming number of submissions were received, most of which were of outstanding quality. Given the length limitations of the special issue, I had to make many hard decisions.

\section{References}

Audi P (2012a) A clarification and defense of the notion of grounding. In: Correia F, Schnieder B (eds) Metaphysical grounding: understanding the structure of reality. Cambridge University Press, Cambridge, pp 101-121 
Audi P (2012b) Grounding: toward a theory of the in-virtue-of relation. J Philos 109:685-711

Baker L (1997) Why constitution is not identity. J Philos 94:599-621

Barnes E (2016) Symmetric dependence. In: Bliss R, Priest G (eds) Reality and its structure. Oxford University Press, New York

Bennett K (2011) By our bootstraps. Philos Perspect 25:27-41

Bennett K (2004) Global supervenience and dependence. Philos Phenomenol Res 68(3):501-529

Berker S (manuscript). The unity of grounding

Block N (2015) The Canberra plan neglects ground. In: Horgan T, Sabatés M, Sosa D (eds) Qualia and mental causation in a physical world: themes from the philosophy of Jaegwon Kim. Cambridge University Press, Cambridge, pp 105-133

Block N, Stalnaker R (1999) Conceptual analysis, dualism, and the explanatory gap. Philos Rev 108(1):1-46

Bolzano B (1972) The theory of science: Die Wissenschaftslehre oder Versuch einer Neuen Darstellung der Logik. In: George R (trans, ed). University of California Press, Berkeley

Braddon-Mitchell D, Jackson F (2007) Philosophy of mind and cognition: an introduction, 2nd edn. Blackwell Publishing, Malden

Braddon-Mitchell D, Nola R (2009) Introducing the Canberra Plan. In: Braddon-Mitchell D, Nola R (eds) Conceptual analysis and philosophical naturalism. MIT, Cambridge, pp 1-20

Bricker P (2006) The relation between the general and the particular: entailment vs. supervenience. In: Zimmerman D (ed) Oxford studies in metaphysics, vol 2. Oxford University Press, Oxford, pp 251-287

Byrne A (1999) Cosmic hermeneutics. Philos Perspect 13:347-383

Cameron RP (2008) Turtles all the way down: regress, priority and fundamentality. Philos Q 58(230):1-14

Chalmers DJ (1996) The conscious mind: in search of a fundamental theory. Oxford University Press, New York

Chalmers DJ (2012) Constructing the world. Oxford University Press, Oxford

Chalmers DJ, Manley D, Wasserman R (eds) (2009) Metametaphysics. Oxford University Press, Oxford

Chomsky N (2000) New horizons in the study of language and mind. Cambridge University Press, Cambridge

Correia F (2010) Grounding and truth-functions. Logique et Analyse 53:251-279

Correia F (2013) Metaphysical grounds and essence. In Hoeltje M, Schnieder B, Steinberg A (eds) Varieties of dependence: ontological dependence, grounding, supervenience, responsedependence, basic philosophical concepts. Philosophia, München, pp 271-296

Correia F, Schnieder B (2012) Grounding: an opinionated introduction. In: Correia F, Schnieder B (eds) Metaphysical grounding: understanding the structure of reality. Cambridge University Press, Cambridge, pp 1-36

Crane T, Mellor H (1990) There is no question of physicalism. Mind 90:185-206

Daly C (2012) Skepticism about grounding. In: Correia F, Schnieder B (eds) Metaphysical grounding: understanding the structure of reality. Cambridge University Press, Cambridge, pp. 81-100

Dasgupta S (2014) The possibility of physicalism. J Philos 111(9/10):557-592

Davidson D (1970) Mental events. Reprint In: Davidson D (ed) 1980 Essays on actions and events. Clarendon Press, Oxford, pp. 207-225

deRosset L (2013) Grounding explanations. Philos. Impr 13(7):1-26

Dove G (2016) Redefining physicalism. Topoi. doi:10.1007/ s11245-016-9405-0

Dowell JL (2006) Formulating the thesis of physicalism: an introduction. Philos Stud 131(1):1-23

Ehring D (2003) Part-whole physicalism and mental causation. Synthese 135(3):359-388
Elpidorou, A. (2014) Blocking the a priori passage. Acta Anal 29(3):285-307

Elpidorou A (manuscript) Part-whole physicalism: the neglected ontological significance of the third logical Investigation

Fine K (1994a) "Essence and Modality". In: Tomberlin JE (ed) Philosophical perspectives 8: logic and language. Ridgeview, Atascadero

Fine K (1994b) Ontological dependence. Proc Aristot Soc 95:269-290

Fine K (2001) The question of realism. Philos Impr 1:1-30

Fine K (2012) "Guide to ground". In: Correia F, Schnieder B (eds) Metaphysical grounding: understanding the structure of reality. Cambridge University Press, Cambridge, pp 37-80

Francescotti R (2010) Realization and physicalism. Philos Psychol 23(5):601-616

Gibb S (2014) The entailment problem and the subset account of property realization. Australas J Philos 92(3):551-566

Gillett C (2002) The dimensions of realization: a critique of the standard view. Analysis 62:316-323

Gillett C (2003) The metaphysics of realization, multiple realizability, and the special sciences. J Philos 100:591-603

Gillett C (2010) Moving beyond the subset model of realization: the problem of qualitative distinctness in the metaphysics of science. Synthese 177:165-192

Hall N (2004) Two concepts of causation. In: Collins J, Hall N, Paul LA (eds) Causation and counterfactuals. MIT, Cambridge, pp 225-276

Hellman G, Thompson FW (1977) Physicalist materialism. Nous 11(4): 309-345

Hempel C (1969) Reduction: ontological and linguistic facets. In: Morgenbesser S, Suppes P, White M (eds), Philosophy, science and method: essays in honor of Ernest Nagel. St. Martin's Press, New York, pp 179-199

Hempel C (1980) Comments on Goodman's Ways of Worldmaking. Synthese 45:139-199

Hill CS (1991) Sensations: a defense of type materialism. Cambridge University Press, Cambridge

Hill CS (2009) The identity theory. In: Bayne T, Cleeremans A, Wilken P (eds) The Oxford companion to consciousness. Oxford University Press, Oxford, pp 359-363

Hofweber T (2009) Ambitious, yet modest, metaphysics. In: Chalmers DJ, Manley D, Wasserman R (eds) (2009) Metametaphysics. Oxford University Press, Oxford, pp. 260-289

Horgan T (1993) From supervenience to superdupervenience: meeting the demands of a material world. Mind 102:555-586

Horgan T (2006) Materialism: matters of definition, defense, and deconstruction. Philos Stud 131(1):157-183

Jackson F (1994) Finding the mind in the natural world. In: Chalmers D (ed) Philosophy of mind: classical and contemporary readings. Oxford University Press, New York, pp 162-169

Jackson F (1998) From metaphysics to ethics: a defence of conceptual analysis. Oxford University Press, Oxford, UK

Jenkins CS (2011) Is metaphysical dependence irreflexive? The Monist 94(2):267-276

Kim J (1984) Concepts of supervenience. Philos Phenomenol Res 45(2): $153-176$

Kim J (ed) (1993a) Supervenience and mind: selected philosophical essays. Cambridge University Press, Cambridge

Kim J (1993b) Postscripts on supervenience. In: Kim J (ed) Supervenience and mind: selected philosophical essays. Cambridge University Press, Cambridge, pp. 161-171

Kim J (1998a) Mind in a physical world: an essay on the mind-body problem and mental causation. MIT, Cambridge

Kim J (1998b) The mind-body problem after fifty years. In: O'Hear A (ed) Current issues in philosophy of mind. Cambridge University Press, Cambridge, pp. 3-21 
Kim J (2005) Physicalism, or something near enough. Princeton University Press, Princeton

Kim J (2010) Thoughts on Sydney Shoemaker's physical realization. Philos Stud 148(1):101-112

Kirk R (2009) Physical realization. Analysis 69(1):148-156

Koslicki K (2015) The coarse-grainedness of grounding. In Bennett K., Zimmerman DW (eds) Oxford studies in metaphysics, vol 9. Oxford University Press, Oxford

Kovacs DM (2016) Grounding and the argument from explanatoriness. Philos Stud. doi:10.1007/s11098-016-0818-9

Kripke S (1980) Naming and necessity. Harvard University Press, Cambridge

Leuenberger S (2008a) Ceteris absentibus physicalism. Oxf Stud Metaphys 4:145-170

Leuenberger S (2008b) Supervenience in metaphysics. Philos Compass 3(4):749-762

Leuenberger S (2009) What is global supervenience? Synthese 170(1):115-129

Leuenberger S (2014) Grounding and necessity. Inquiry 57:151-174

Levine J (1993) On leaving out what it's like. In: Davies M, Humphreys G (eds) Consciousness: psychological and philosophical essays. Blackwell, Oxford, pp 121-136

Levine J, Trogdon K (2009) The modal status of materialism. Philos Stud 145:351-362

Lewis D (1966) An argument for the identity theory. J Philos 63:17-25

Lewis D (1970) How to define theoretical terms. J Philos 67:427-446

Lewis D (1972) Psychophysical and theoretical identifications. Australas J Philos 50(3):249-258

Lewis D (1983) New work for a theory of universals. Australas J Philos 61:343-377

Lewis D (1986) On the plurality of worlds. Blackwell, Oxford

Lewis D (1994) Reduction of mind. In: Guttenplan S (ed) A companion to the philosophy of mind. Basil Blackwell, Oxford, pp 51-63

Loewer B (2001) From physics to physicalism. In: Gillet C, Loewer B (eds) Physicalism and its discontents. Cambridge University Press, Cambridge, pp 37-56

Lynch MP, Glasgow JM (2003) The impossibility of superdupervenience. Philos Stud 113(3):201-221

McLaughlin B (2009) Review of Sydney Shoemaker's physical realization. Notre Dame Philos Rev 50: 249-258

McLaughlin B, Bennett K (2014) Supervenience. In Zalta EN The stanford encyclopedia of philosophy. http://plato.stanford.edu/ archives/spr2014/entries/supervenience

Melnyk A (1997) How to keep the 'physical' in physicalism. J Philos 94:622-637

Melnyk A (2003) A physicalist manifesto: thoroughly modern materialism. Cambridge University Press, Cambridge

Melnyk A (2006) Realization and the formulation of physicalism. Philos Stud 131(1):127-155

Melnyk A (2016a) In defense of a realization formulation of physicalism. Topoi. doi:10.1007/s11245-016-9404-1

Melnyk A (2016b) Grounding and the formulation of physicalism. In: Aizawa K, Gillett C (eds) Scientific composition and metaphysical ground. Palgrave Macmillan, London, pp 249-270

Montero BG (2006) Physicalism in an infinitely decomposable world. Erkenntnis 64(2):177-191

Montero BG (2013) Must physicalism imply the supervenience of the mental on the physical? J Philos 110(2):93-110

Montero BG, Brown C (2017) Making room for a this-wordly physicalism. Topoi. doi:10.1007/s11245-017-9450-3

Morris K. (2016) Physicalism, truthmaking, and levels of reality: prospects and problems. Topoi. doi:10.1007/s11245-016-9379-y

Ney A (2008a) Physicalism as an attitude. Philos Stud 138(1):1-15
Ney A (2008b) Defining physicalism. Philos Compass 3(5):1033-1048

Nolan D (2005) David Lewis. Acumen, Chesham

Paull RC, Sider TR (1992) In defense of global supervenience. Research 52(4):833-854

Pereboom D (2011) Consciousness and the prospects of physicalism. Oxford University Press, Oxford

Pereboom D (2016) Anti-reductionism, anti-rationalism, and the material constitution of the mental. In: Aizawa K, Gillett C (eds) Scientific composition and metaphysical ground. Palgrave Macmillan, London, pp 123-140

Pettit P (1995) Microphysicalism, dottism and reduction. Analysis 55(3):141-146

Poland J (1994) Physicalism: the philosophical foundations. Clarendon, Oxford

Polger T (2004) Natural minds. MIT Press, Cambridge

Polger T (2007) Realization and the metaphysics of mind. Australas J Philos 85:233-259

Polger TW, Shapiro LA (2008) Understanding the dimensions of realization. J Philos 105(4):213-222

Quine WV (1948) On what there is. Rev Metaphysics 2(1):21-38

Raven M (2012) In defense of ground. Australas J Philos 90:687-701

Raven M (2015) Ground. Philos Compass 10(5):322-333

Rosen G (2010) Metaphysical dependence: grounding and reduction. In: Hale R, Hoffman A (eds), Modality: metaphysics, logic, and epistemology. Oxford University Press, New York, NY, pp $109-136$

Schaffer J (2003) Is there a fundamental level? Noûs 37(3):498-517

Schaffer J (2009) On what grounds what. In: Chalmers DJ, Manley D, Wasserman R (eds) Metametaphysics. Oxford University Press, Oxford, pp. 347-383

Schaffer J (2010) The internal relatedness of all things. Mind 119 (474):341-376

Schaffer J (2012) Grounding, transitivity, and contrastivity. In: Correia F, Schnieder B (eds) Metaphysical grounding: understanding the structure of reality. Cambridge University Press, Cambridge, pp. $122-138$

Schaffer J (2016) Grounding in the image of causation. Philos Stud 173(1):49-100

Schiffer S (1987) Remnants of meaning. MIT/Bradford, Cambridge

Schnieder B (2006) Truth-making without truth-makers. Synthese 152:21-46

Schwarz W (2015) Analytic functionalism. In: Loewer B, Schaffer J. (eds) A companion to David Lewis. Wiley Blackwell, Malden, pp. 504-518

Shagrir O (1999) More on global supervenience. Res 59(3):691-701

Shoemaker S (1980) "Causality and properties", reprinted in identity, cause, and mind: philosophical essays (Expanded Edition). Oxford University Press, Oxford

Shoemaker S (2001) Realization and mental causation. In: Gillett C, Loewer B (eds) Physicalism and its discontents. Cambridge University Press, Cambridge

Shoemaker S (2007) Physical realization. Oxford University Press, Oxford

Shoemaker S (2011) Realization, powers, and property identity. The Monist 94(1):3-18

Sider T (2011) Writing the book of the world. Oxford University Press, Oxford

Skiles A (2015) Against grounding necessitarianism. Erkenntnis 80(4):717-751

Smart JJC (1959) Sensations and brain processes. Philos Rev 68(2):141-156

Smart JJC (2007) The mind/brain identity theory. In: Zalta EN (ed), The Stanford Encyclopedia of Philosophy. https://plato.stanford. edu/archives/spr2017/entries/mind-identity 
Stalnaker R (1996) "Varieties of supervenience". Philos Perspect 10:221-241

Stoljar D (2010) Physicalism. Routledge, New York

Stoljar D (2015) Physicalism. In: Zalta EN (ed) The Stanford encyclopedia of philosophy. http://plato.stanford.edu/archives/spr2016/ entries/physicalism

Tahko TE, Lowe EJ (2015) Ontological dependence. In: Zalta EN (ed) The stanford encyclopedia of philosophy. http://plato.stanford.edu/archives/spr2015/entries/dependence-ontological/

Tatzel A (2002) Bolzano's theory of ground and consequence. Notre Dame. J Symb Logic 43:1-25

Teller P (1984) Comments on Kim's paper. South J Philos 22(S1):57-61

Trogdon K (2013a) An introduction to grounding. In: Hoeltje M, Schnieder B, Steinberg A (eds) Varieties of dependence: ontological dependence, grounding, supervenience, responsedependence, basic philosophical concepts. Philosophia, München, pp. 97-122

Trogdon K (2013b) Grounding: necessary or contingent? Pac Philos Q 94:465-485

van Fraassen B (2002) The empirical stance. Yale University Press, New Haven
Watkins M (2002) Rediscovering colors: a study in pollyanna realism, vol 88. Springer, Berlin

Wilson J (1999) How superduper does a physicalist supervenience need to be? Philos Q 49:33-52

Wilson J (2005) Supervenience-based characterizations of physicalism. Noûs 39:426-459

Wilson J (2009) Determination, realization, and mental causation. Philos Stud 145(1):149-169

Wilson J (2011) Non-reductive realization and the powers-based subset strategy. The Monist 94(1):121-154

Wilson J (2014) No work for a theory of grounding. Inquiry 57(5-6):1-45

Wilson J (2016) Grounding-based formulations of physicalism. Topoi. doi:10.1007/s11245-016-9435-7

Wilson A (2017) Metaphysical causation. Noûs. doi:10.1111/ nous. 12190

Witmer G (2001) Sufficiency claims and physicalism: a formulation. In: Gillett C, Loewer B (eds) Physicalism and its discontents. Cambridge University Press, Cambridge, pp 57-73

Witmer G (2016) Physicality for physicalists. Topoi. doi:10.1007/ s11245-016-9415-y

Yablo S (1992) Mental causation. Philos Rev 101(2):245-280 